\title{
Investigating Obesity Related Behaviours in Friendship Networks Among the Youth: A Systemized Review
}

\section{Noor Alsayed ${ }^{1}$, Tillal Eldabi ${ }^{1,2}$, and Habin Lee ${ }^{1}$}

${ }^{1}$ College of Business, Arts and Social Sciences, Brunel University London, UK

${ }^{2}$ College of Business \& Finance, Ahlia University, Bahrain

\section{Abstract}

Background: Unhealthy diet, low levels of physical activity and increased participation in sedentary activities are important obesity related behaviours that negatively impact the health of today's youth. Friends' health behaviours have been found to influence the individual health behaviours; however current evidences on the specific role of friendship networks on obesity related behaviours are inconclusive. The purpose of this review is to profile the existing literature in an attempt to identify the associations between friendship networks and obesity related behaviours among adolescents.

Corresponding Author:

Noor Alsayed

Received: 22 July 2019

Accepted: 16 September 2019

Published: 19 September 2019

Publishing services provided by

Knowledge $\mathrm{E}$

(c) Noor Alsayed et al. This article is distributed under the terms of the

Attribution License, which

permits unrestricted use and redistribution provided that the original author and source are credited.

Selection and Peer-review under the responsibility of the PwR Symposium Conference Committee.
Method: A systemized review of the literature was undertaken after a search of the Scopus database, a total of fifteen articles were eligible for inclusion. The selected publications assessed the association between friendship networks and obesity related behaviours (diet, physical activity, and sedentary behaviour) among the youth.

Results: There is consistent evidence that friends are similar in physical activity; evidence on diet and sedentary behaviour is mixed and limited. Friendship network characteristics seem to associated with obesity related behaviours. Popularity (receiving ties) is likely to be associated with diet, network size and the proportion of active friends is tends to be associated with physical activity and finally network density is associated with sedentary behaviour.

Conclusion: Friendships are critical in shaping young people's obesity related behaviours.. There is extensive research investigating friendship influences on diet physical activity and sedentary behaviour. Future studies should investigate whether friendship influence operate via other obesity related behaviours that have not been explored yet such as sleep. Results from this review are informative for designing effective public health interventions because network based promotion interventions have a promising potential.

Keywords: Social Networks, Friendship, Diet, Physical Activity, Sedentary Behaviour, Obesity

\section{Background/Introduction}


increased participation in sedentary behaviour are important behaviours that have contributed to the increased prevalence of obesity among the youth (Wang and Lobstein, 2006). One of the main hypothesized causes of the continued increase in obesity is that current preventative measures are individually targeted and they lack the proper understanding of obesity within the social context (i.e. the effect of social networks) (Nam, Redeker and Whittemore, 2015). The term social networks refer to a set of individuals and the ties among them (Wasserman and Faust, 1994). Social networks pervade our lives on a daily basis: we interact, influence, and are influenced by our friends and acquaintances (Pinheiro et al., 2014). Christakis and Fowler were the first to find that obesity spreads over social network (Christakis and Fowler, 2007). The findings of their study were somewhat controversial as it offered evidence that obesity may spread like an infection. Several studies followed to investigate the sensitivity of Christakis and Fowler's claim and assess the nature and extent of the person to person spread of obesity and could not dismiss their findings (Cohen Cole and Fletcher, 2008: Bahr et al., 2009). Christakis and Fowler's study generated significant interest where the idea of communicability (contagiousness) of obesity was originated. It is increasingly acknowledged that social networks are important to our understanding of obesity (Powell et al., 2015). The specific dynamic mechanisms underlying the spread of obesity remains an important gap in the literature, and is the focus of a growing body of research (Burke \&Heiland, 2006; Bahr et al., 2009; Shoham et al., 2012). The social transmission of weight-related behaviours is a viable explanation for the spread of obesity in friendship networks that has been documented in recent research (Ali, Amialchuk and Heiland, 2011). A better understanding of the role of friendship networks on obesity related behaviours is important in order to learn how to modify these behaviours. Especially that, unlike genetics, obesity related behaviours including diet, physical activity, sedentary behaviour and sleep deprivation are somewhat modifiable.

There are multiple processes to explain the similarity of behaviours in friendship networks. The process of social selection or homophile (the tendency for individuals to select individuals with similar behviours) and peer influence (influencing the individual to change his behaviour) (Valente, 2010). Several mechanisms may explain the process of peer influence including modelling (engaging in a behaviour after observing a peer), peer pressure (directly imposing a behaviour on a peer), group norms (a collection of attitudes shared by a group of peers) and co participation (engaging in a behaviour with a friend) (Prinstein and Dodge, 2008). Recently, there has 
been a growing interest in studying the effects of social networks including friendship networks on obesity and obesity related behaviours by undertaking social network analysis. Social network analysis is the structural approach based on the social ties between individuals (Freeman, 2004). The approach is focused on the patterns and implications of the social ties between the individuals because these ties have important consequences on their behaviour (Wasserman \& Faust, 1994). Social network analysis can unveil how relationships enable health behaviours (Shoham et al., 2015).

Although there is consistent evidence that friends are similar in physical activity; evidence on diet and sedentary behaviour is mixed and limited (Ali, Amialchuk and Heiland, 2011; Geller et al., 2013; Sawka et al., 2013). Friendship networks have been linked to obesity related behaviours; however, network characteristics have not been broadly examined (Sawka et al., 2014). Several gaps in current knowledge, include the lack of evidence regarding the association between social network ties, roles, positions, characteristics and diet, physical activity and sedentary behaviour (Sawka et al., 2013). The aim of this review is to synthesize existing literature on associations between friendship networks and obesity related behaviours among the youth by undertaking a systemized review. A systematized review encompasses multiple, but not all aspects of a complete systematic review (Grant and Booth, 2009). The objectives of the review are to: 1) examine association between a friend's obesity related behaviours (diet, physical activity and sedentary behaviour) and the obesity related behaviours (diet, physical activity and sedentary behaviour) of the individual 2 ) identify different types of social network measures/variables (such as network size, density, position etc) and examine associations between them and obesity related behaviours (diet, physical activity and sedentary behaviour).

\section{Method}

To identify the relevant studies, the database Scopus was searched. The following search terms were combined for the network effects (social networks, friend, friendship, peer) and for the obesity related behaviours (diet, eating, physical activity, sedentary behaviour, screen time). Searches were restricted to English peer reviewed journal articles. Scopus was searched in August, 2016. There was more than 3,000 articles returned after combining the search terms (each search a network effects search term and an obesity related behaviour search term were used). The screening process was done at three different stages including screening by title, 
screening by abstract and finally a full paper review. The first stage assessed the titles of the articles and after removing the duplicates 89 articles were eligible. The 89 remaining articles were then screened by abstract and a total of 25 articles were identified for a full paper review. A full paper review of the remaining 25 articles resulted in 14 relevant articles as shown in Figure 1 below. The criteria for selection was articles published in the last ten years studying the influence of social/friendship networks on obesity related behaviours among youth (below 21).

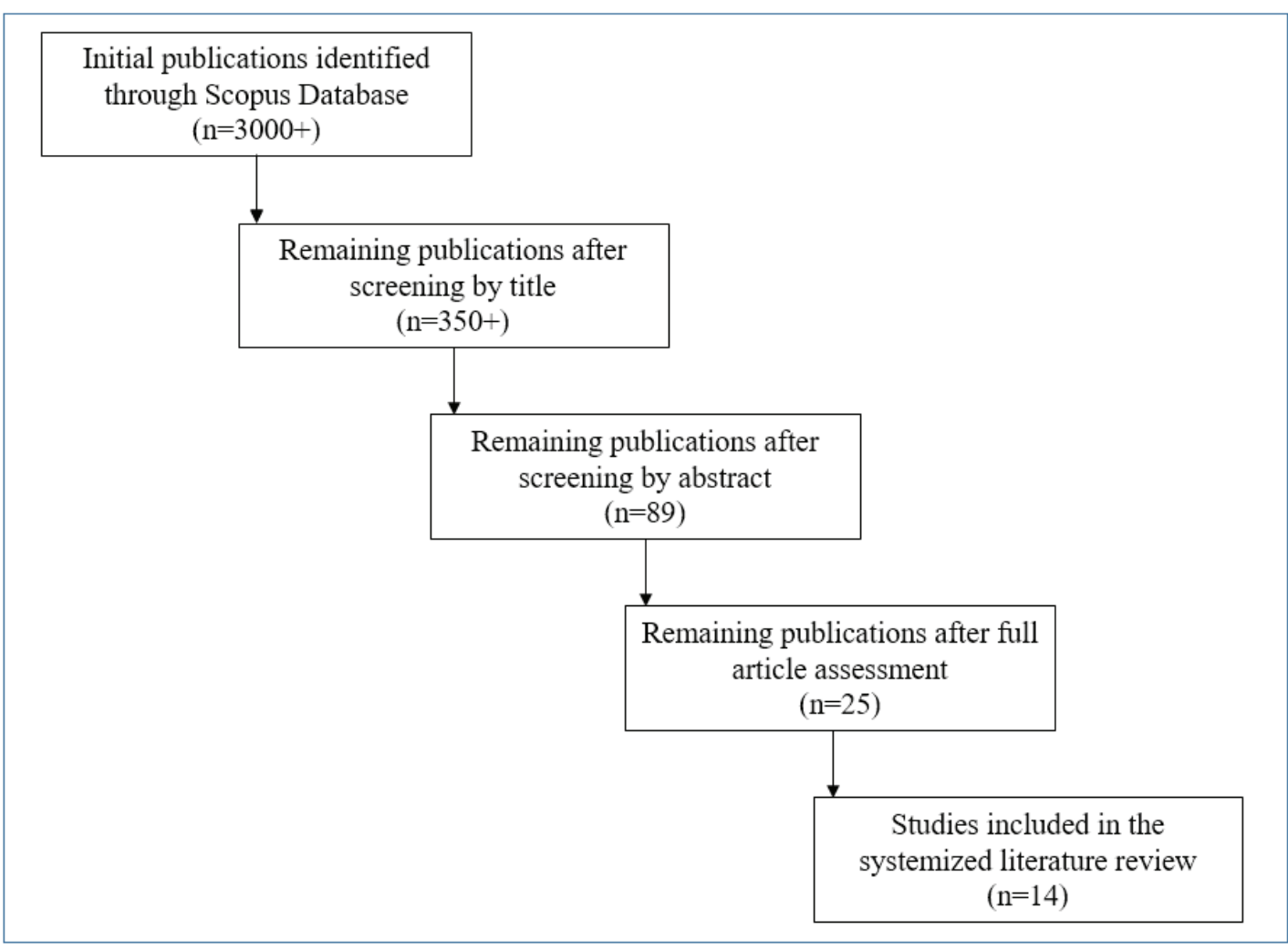

Figure 1: Diagram for article search and selection.

\section{Results}

A total of fourteen studies were included in this review. A table with a full description of the included studies is available in Appendix A. The below sections will present the findings: 


\subsection{Characteristics of the reviewed studies}

A total of 14 articles met the inclusion criteria. The included studies were interested mainly in adolescents between the ages 12 to $18(n=12)$, young adults aged $19(n=1)$ and children between the ages 8 to $12(n=1)$. The types of studies included literature review studies $(n=2)$, primary data studies $(n=9)$ and secondary data studies $(n=3)$. The majority of the studies employed quantitative methods $(n=10)$, and the remaining studies used mixed methods, employing both quantitative and qualitative instruments $(n=2)$. The geographical locations of the studies were USA $(n=6)$, Australia $(n=4)$, Canada $(n=2)$, United Kingdom $(n=1)$ and Sweden $(n=1)$. The studies followed a cross-sectional study design $(n=7)$ and a longitudinal study design $(n=5)$. The selected studies that use data (both primary and secondary) investigate associations between friends/peers and one or more obesity related behaviour, in addition to associations between one or more obesity related behaviour and one or more network variable as summarized in Table 1 below. Most of the studies investigated associations between friends or peers associations with one or more obesity related behaviour ( $n=11)$ as presented in Table 1 below. The majority of the studies investigated physical activity $(n=10)$, followed by diet $(n=6)$ and sedentary behaviour ( $n=6)$ as presented in Table 1 below. Some of the studies investigated associations between obesity related behaviours and networks variables including size $(n=1)$, density $(n=2)$, popularity $(n=4)$, centrality $(n=1)$, clique membership $(n=2)$, and proportion of friends engaging in a certain obesity related behaviour $(n=2)$ as presented in Table 1 below.

TABLE 1: Studies investigating associations between friends/peers, obesity related behaviours and network variables.

\begin{tabular}{|c|c|c|c|c|c|c|c|c|c|c|}
\hline \multirow[b]{2}{*}{ Publication } & \multirow{2}{*}{$\begin{array}{c}\text { Association } \\
\text { between } \\
\text { friends/peers }\end{array}$} & \multicolumn{3}{|c|}{ Obesity related Behaviour } & \multicolumn{6}{|c|}{ Network Variable } \\
\hline & & Diet & $\begin{array}{l}\text { Physical } \\
\text { Activity }\end{array}$ & $\begin{array}{l}\text { Sedentary } \\
\text { behaviour }\end{array}$ & Size & Density & Popularity & Centrality & $\begin{array}{c}\text { Clique } \\
\text { membership }\end{array}$ & $\begin{array}{c}\text { Proportion of } \\
\text { friends }\end{array}$ \\
\hline Ali, Amialchuk and Heiland, 2011 & $\checkmark$ & $\checkmark$ & $\sqrt{ }$ & $\checkmark$ & & & & & & \\
\hline Barclay, Edling and Rydgren, 2013 & $\sqrt{ }$ & $\sqrt{ }$ & $\sqrt{ }$ & & & & & & & \\
\hline de la Haye et al., 2010 & $\sqrt{ }$ & $\checkmark$ & $\checkmark$ & $\checkmark$ & $\checkmark$ & $\checkmark$ & $\checkmark$ & & $\checkmark$ & \\
\hline de la Haye et al., 2011 & $\checkmark$ & & $\checkmark$ & & & & & & & \\
\hline de la Haye et al., 2013 & $\checkmark$ & $\checkmark$ & & & & & $\checkmark$ & & & \\
\hline Finnerty et al., 2009 & $\checkmark$ & $\checkmark$ & $\checkmark$ & & & & & & & \\
\hline Garcia et al., 2016 & $\checkmark$ & & $\checkmark$ & $\checkmark$ & & & & & & \\
\hline Geller et al., 2013 & $\checkmark$ & $\checkmark$ & $\checkmark$ & $\sqrt{ }$ & & & & & & \\
\hline Marks et al., 2015 & $\checkmark$ & & $\sqrt{ }$ & $\sqrt{ }$ & & & & & & $\checkmark$ \\
\hline Sawka et al., 2014 & $\checkmark$ & & $\sqrt{ }$ & $\sqrt{ }$ & $\checkmark$ & $\checkmark$ & $\sqrt{ }$ & $\checkmark$ & $\checkmark$ & $\checkmark$ \\
\hline Simpkins et al., 2013 & $\checkmark$ & & $\checkmark$ & & & & $\checkmark$ & & & \\
\hline
\end{tabular}




\subsection{Associations between friendship networks and diet}

There is a significant positive association between individuals' and friends' fast food consumption (Ali, Amialchuk and Heiland, 2011). Friends being similar on food consumption behaviours is a potential mechanism for the social 'contagion' of obesity (de la Haye et al., 2010). Individuals also have a significantly greater probability of eating healthily if a nominated peer also does so (Barclay, Edling and Rydgren, 2013). Additionally, the degree to which this behaviour is shared is positively correlated with the strength of the relationship between the two individuals (Barclay, Edling and Rydgren, 2013). The findings of some of the studies are gender specific which has implications for gender tailored interventions (de la Haye et al., 2010; Finnerty et al., 2009). One important friendship network property is popularity (i.e receiving ties) which was found to be associated with consumption of unhealthy snacks among males which means popular boys were the highest consumers of unhealthy snacks (de la Haye et al., 2010) as shown in Table 2 below. Male friends were also found to be similar in their consumption of high calorie foods (de la Haye et al., 2010). Although adolescent intake of unhealthy foods was predicted by their friends' intake; the changes to adolescents' beliefs about unhealthy foods do not appear to be the underlying mechanism of influence from their friends (de la Haye et al., 2013). There seems to be mixed evidence on peer and friends influences on individuals in the literature. Some researchers found no evidence of peer or friend influence on individuals' dietary habits (Finnerty et al., 2009; Geller et al., 2013). Parents/ guardians had the dominant influence on adolescents' dietary behaviours in comparison to their friends (Geller et al., 2013)

\subsection{Associations between friendship networks and physical activ- ity}

There is significant positive association between individuals' and friends' sports and exercise (Ali, Amialchuk and Heiland, 2011). Individuals tended to befriend peers who did similar amounts of physical activity and consequently emulated their friends' behaviours: however, friends' influence on physical activity was not found to be mediated through cognitions about physical activity (de la Haye et al., 2011). Friends' physical activity level have a significant influence on individual's physical activity level (Sawka et al., 2013). Higher levels of friends' MVPA (moderate to vigorous physical activity) was associated with higher levels of MVPA among males and females (Garcia et al., 2016). There is a mutually dependent relationship between adolescent friendship networks 
and physical activity (de la Haye et al., 2011). Friends become similar in BMI and physical activity over time however physical activity as measured in this study was not found to explain friendship similarity on BMl, but several other potential mechanisms could be further explored (Simpkins et al., 2013). Focus group data revealed that friends positively influenced participants' MVPA through engaging in activities with participants, verbal encouragement, and modelling; the most cited reason for engaging in MVPA with friends was enjoyment (Garcia et al., 2016). Children's physical activity was positively associated with encouragement from friends, friends' own physical activity and engagement with friends in physical activity (Maturo and Cunningham, 2013). Different friendship network characteristics (density; proportion of active friends; betweenness centrality; popularity) appeared to have different consequences on physical activity; the proportion of active close friends was associated with MVPA (Sawka et al., 2014).

Additionally the size of children/adolescents' friendship groups is associated with physical activity (de la Haye et al., 2010) as shown below in table 2.

\subsection{Associations between friendship networks and sedentary behaviour}

Evidence surrounding friendship influence on individual sedentary behaviour is limited and mixed (Sawka et al., 2013). There is no consistent evidence in support of peer effects on TV viewing (Ali, Amialchuk and Heiland, 2011). One study found female friends to engage in similar screen based behaviours (de la Haye et al., 2010). Another study found that males screen time was associated with higher levels of screen time among their friends (Garcia et al., 2016). Friendship network characteristics were found to be associated with sedentary/screen time in late childhood/early adolescence, however these associations differ by gender (Marks et al., 2015). Different friendship network characteristics (density; proportion of active friends; betweenness centrality; popularity) appeared to have different consequences on sedentary behaviour; network density was associated with sedentary behaviour among boys so boys in dense networks were found to be highly sedentary (Sawka et al., 2014) as shown below in 
TABLE 2: Studies that found evidence for associations between friends/peers, network variables and obesity related behaviours.

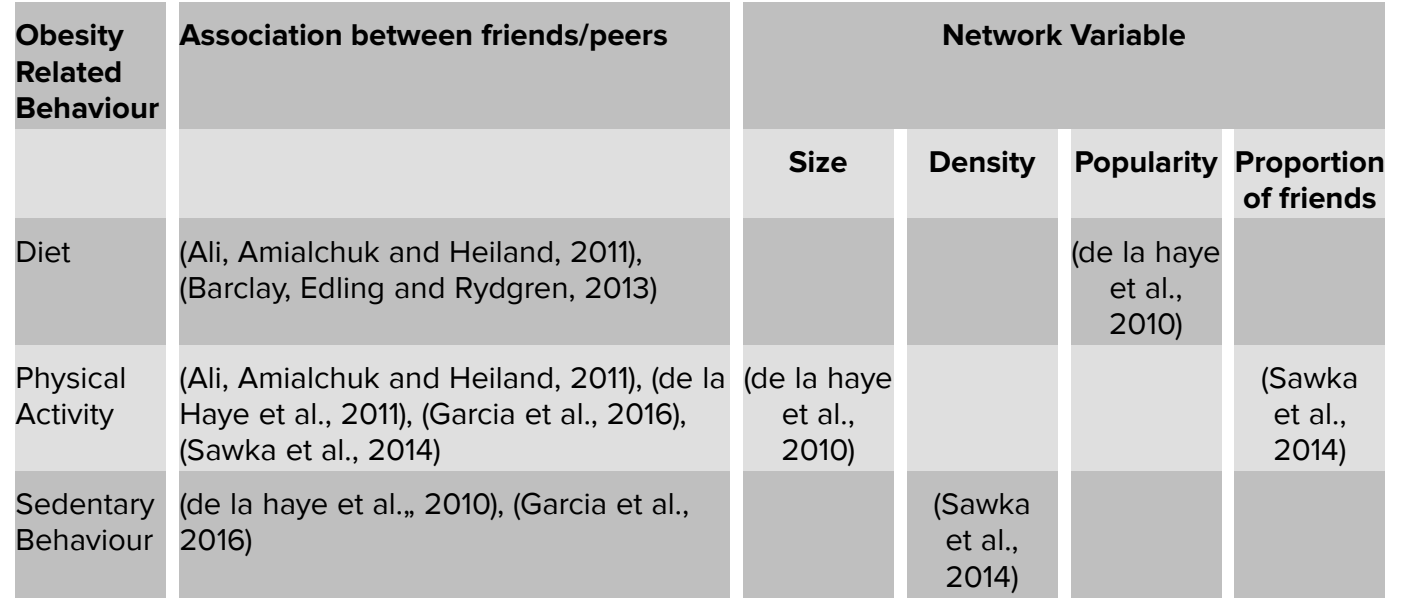

\section{Discussion}

There are strong associations between egos and alter health behaviours for the youth which suggests that health behaviours of an individual's peers plays a role in shaping their own health behaviours (Barclay, Edling and Rydgren, 2013). Higher Body Mass Index (BMI) of close friends is correlated with a higher BMI of the individual (Renna, Grafova and Thakur, 2008). One of the hypothesized causes of the similarities in higher BMI among friends is the similarities in obesity related behaviours including diet, physical activity and sedentary behaviour. Peers and friends are found to have a significant effect on physical activity levels (Finnerty et al., 2009). When it comes to diet, there are mixed findings in the literature on the similarities in diet among friends. Some researchers found similarities in diet among friends (healthy and unhealthy diets) (Ali, Amialchuk and Heiland, 2011; de la Haye et al., 2010; de la Haye et al., 2013; Barclay, Edling and Rydgren, 2013); whereas others found no effect of friends on individuals diet (Finnerty et al., 2009; Geller et al., 2013). Evidence surrounding friendship influence on individual sedentary behaviour is also limited and mixed (Sawka et al., 2013). This offers important implications for the design of health promotion interventions and obesity prevention programmes (Finnerty et al., 2009). Network-based strategies may be effective in supporting individuals to be physically active (de la Haye et al., 2010). Adolescents are more responsive to the body weight of their same gender friends (Renna, Grafova and Thakur, 2008). So there is also a need for gender specific interventions (Finnerty et al., 2009). Friendship network characteristics are associated with some obesity related behaviours, however these associations differ by gender (Marks et al., 2015). Different friendship network characteristics (density; proportion of active friends; betweenness centrality; popularity) appeared to have different consequences on diet, 
physical activity and sedentary behaviour. Popularity(receiving ties) was associated with consumption of unhealthy snacks among boys, the proportion of active close friends was associated with higher levels of physical activity among boys and firls, finally network density was associated with sedentary behaviour among boys (de la Haye et al., 2010; Sawka et al., 2014). Friendships networks have been linked to obesity related behaviours; however, network characteristics have not been broadly examined (Sawka et al., 2014).

\section{Conclusion}

A high caloric diet, low levels of physical activity and increased participation in sedentary behaviour are important behaviours that have contributed to the increased prevalence of obesity (Wang and Lobstein, 2006).The spread of obesity related behaviours is a potential mechanism by which obesity may spread over friendship networks (Ali, Amialchuk and Heiland, 2011). A growing body of literature explored associations between friendship network characteristics, diet physical activity, and sedentary behaviours (de la Haye et al., 2010; Garcia et al., 2016; Geller et al., 2013; Marks et al., 2015; Renna, Grafova and Thakur, 2008; Sawka et al., 2013; Sawka et al., 2014).. Friendship networks have been linked to obesity related behaviours; however, network characteristics have not been extensively examined (Sawka et al., 2014). Also, there is evidence that friends influence the individuals' physical activity levels; the evidence is less clear for diet and sedentary behaviours (de la Haye et al., 2011; Geller et al., 2013; Sawka et al., 2013). More investigative research is necessary to clarify the role of friendship networks on diet and sedentary behaviour. Future studies in different cultural contexts and different clinical samples are required (Tonetti et al., 2014). Future studies should investigate whether friendship networks influence obesity via other pathways (Ali, Amialchuk and Heiland, 2011). Sleep deprivation (an important predictor of obesity) has generally been neglected in the social networks literature (Maume, 2013). Results from this review are informative for designing effective interventions that could utilize the influence of friends to increase physical activity levels among children, adolescents and young adults.

\section{References}

[1] Ali, M., Amialchuk, A. and Heiland, F. (2011). Weight-Related Behaviour among

[2] Adolescents: The Role of Peer Effects. PLoS ONE, 6(6), p.e21179. 

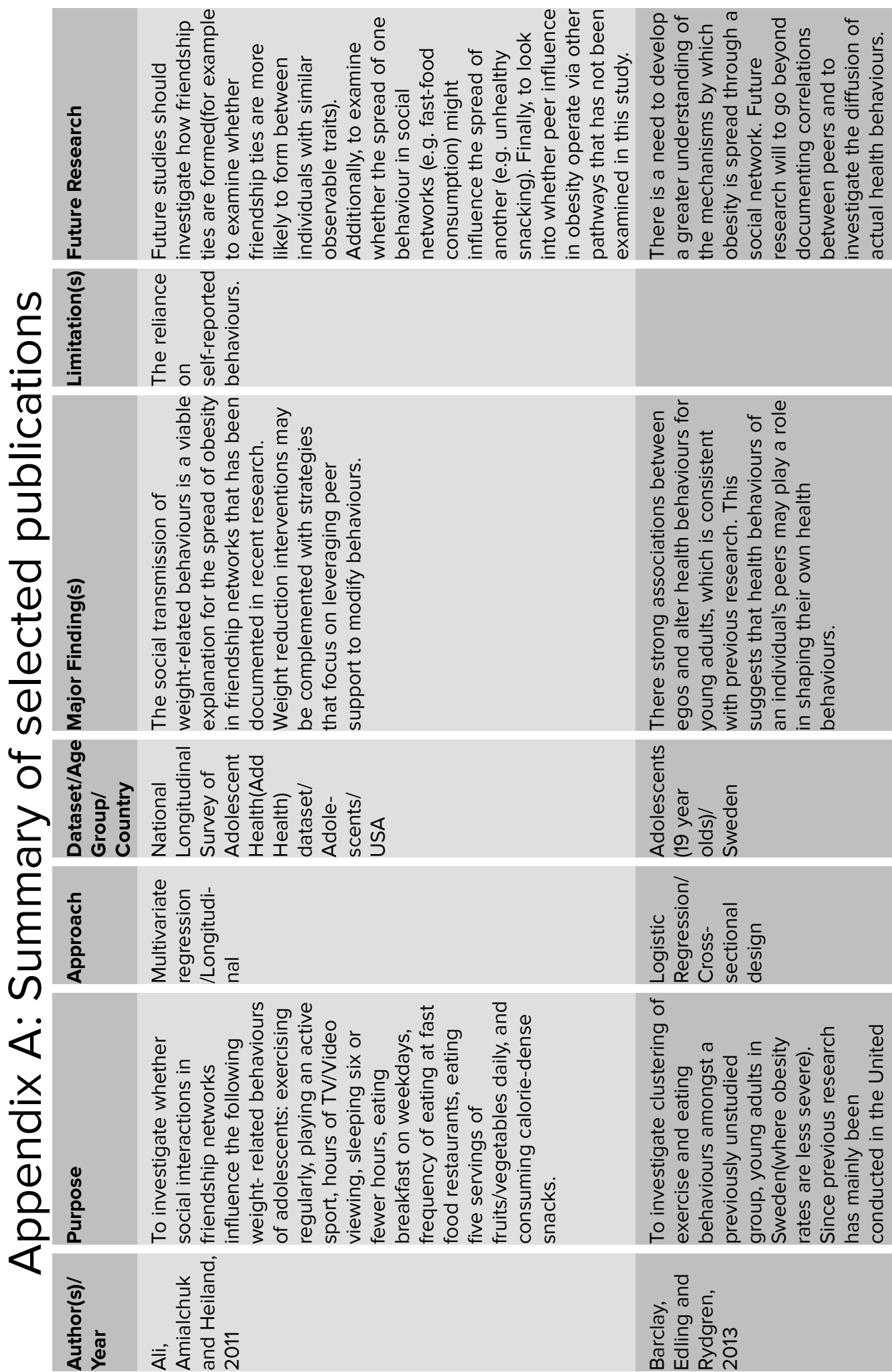

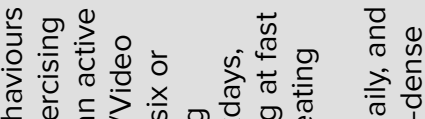

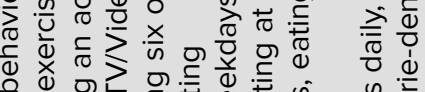
व

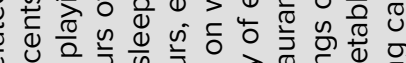

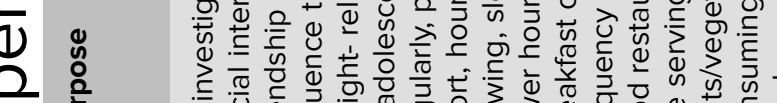

人

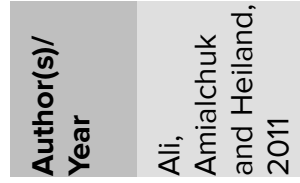

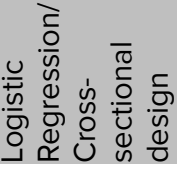

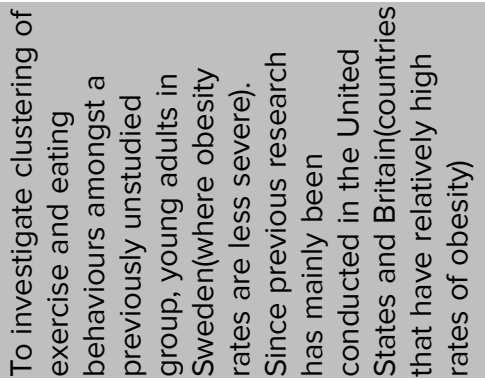

\begin{tabular}{|c|}
\hline 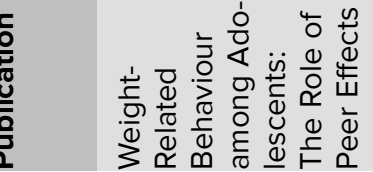 \\
\hline
\end{tabular}

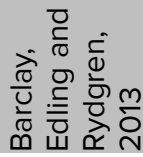

$\dot{8}$

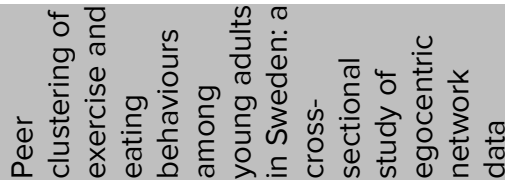



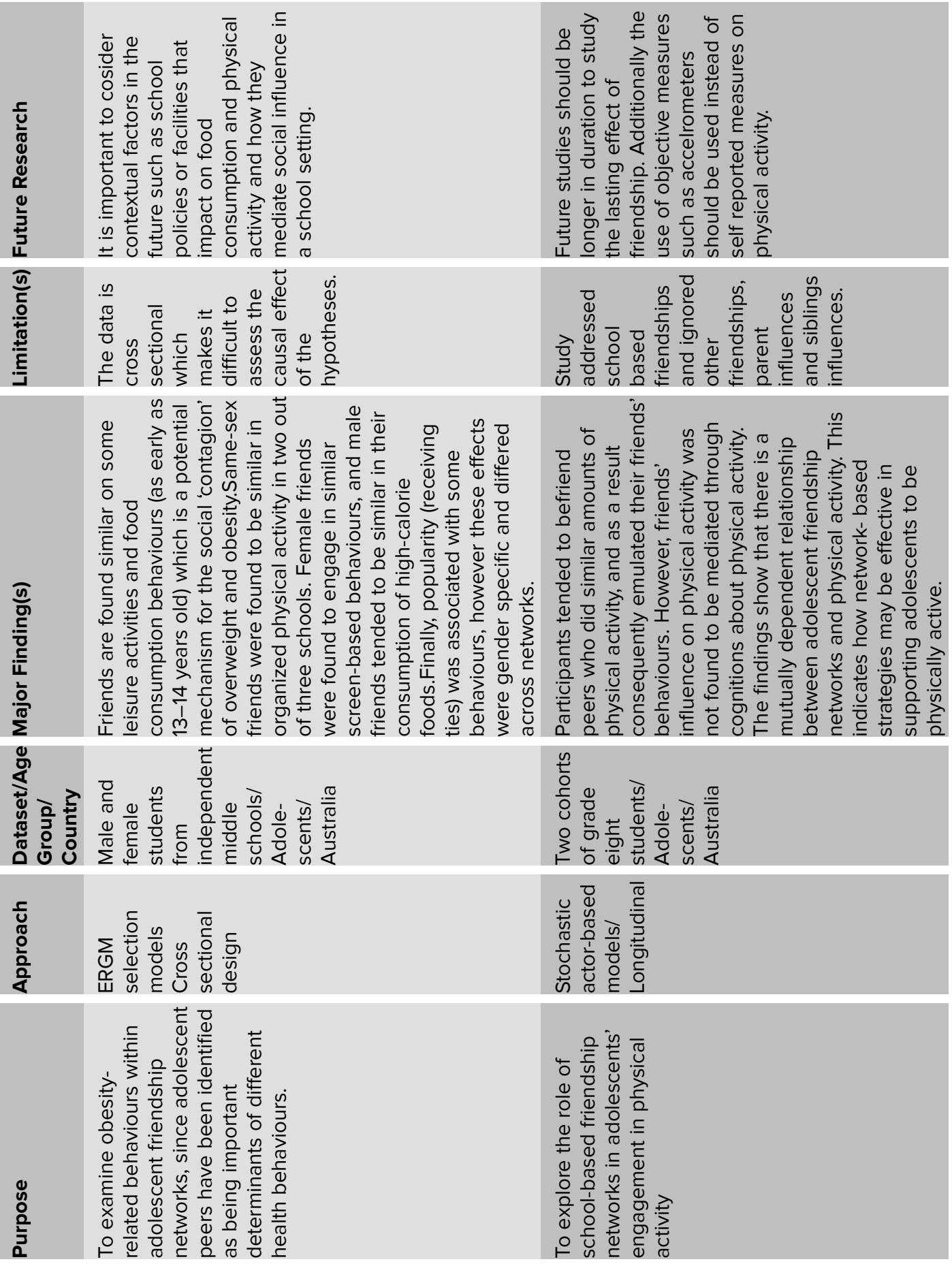

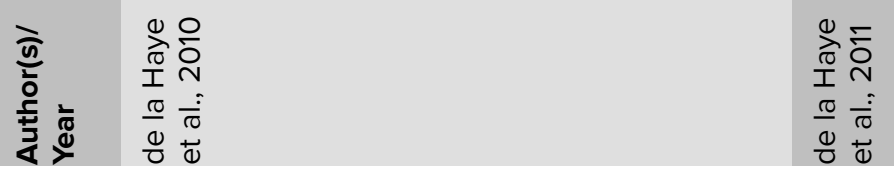

\begin{tabular}{|c|c|c|}
\hline $\begin{array}{l}\tau \\
\frac{0}{\pi} \\
\frac{0}{0} \\
\frac{0}{30} \\
0.0\end{array}$ & 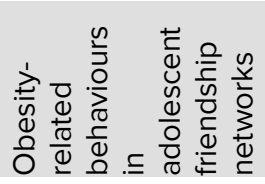 & 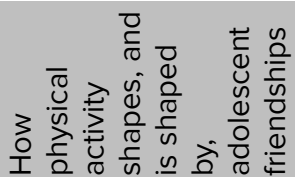 \\
\hline & $m$ & ナ \\
\hline
\end{tabular}



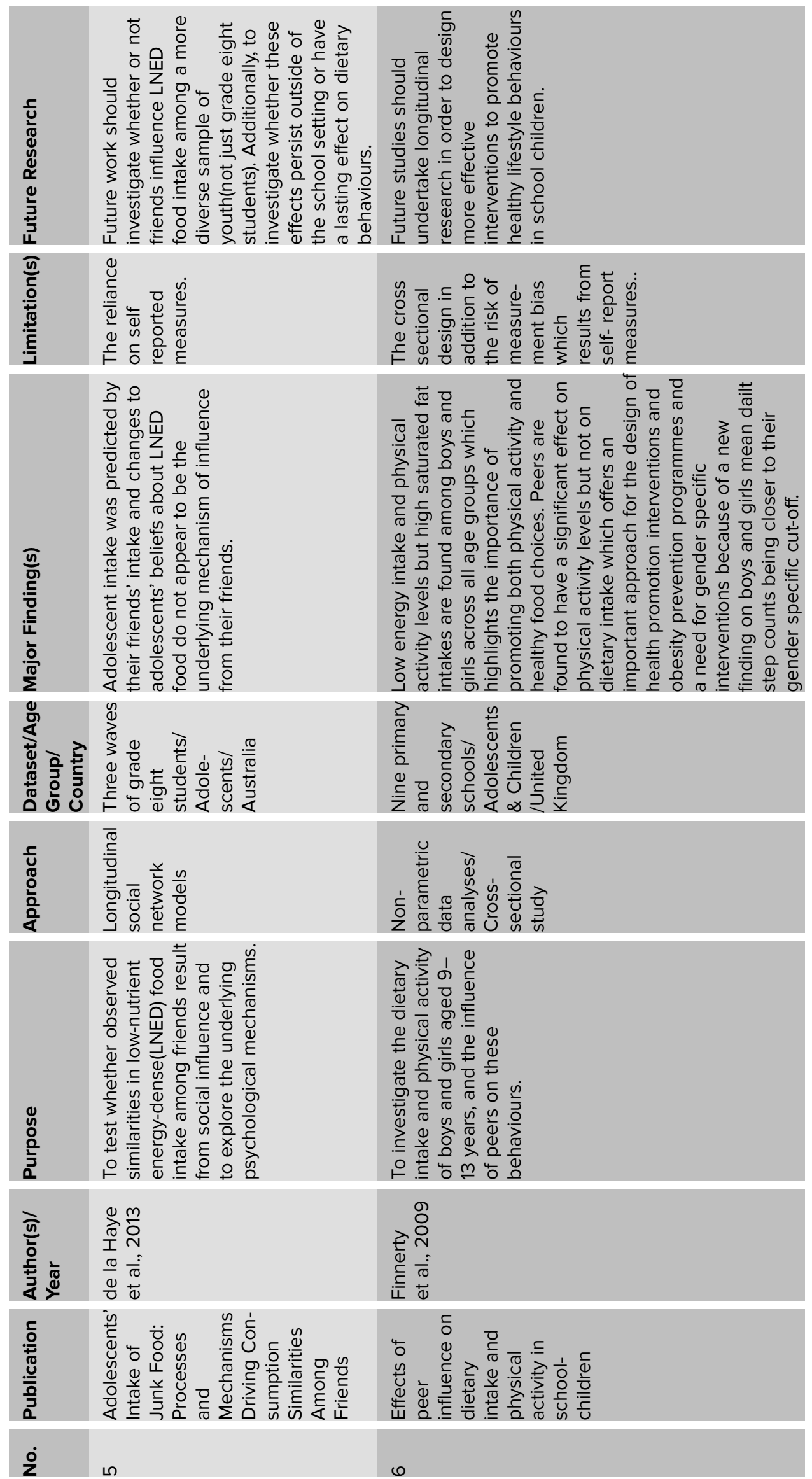


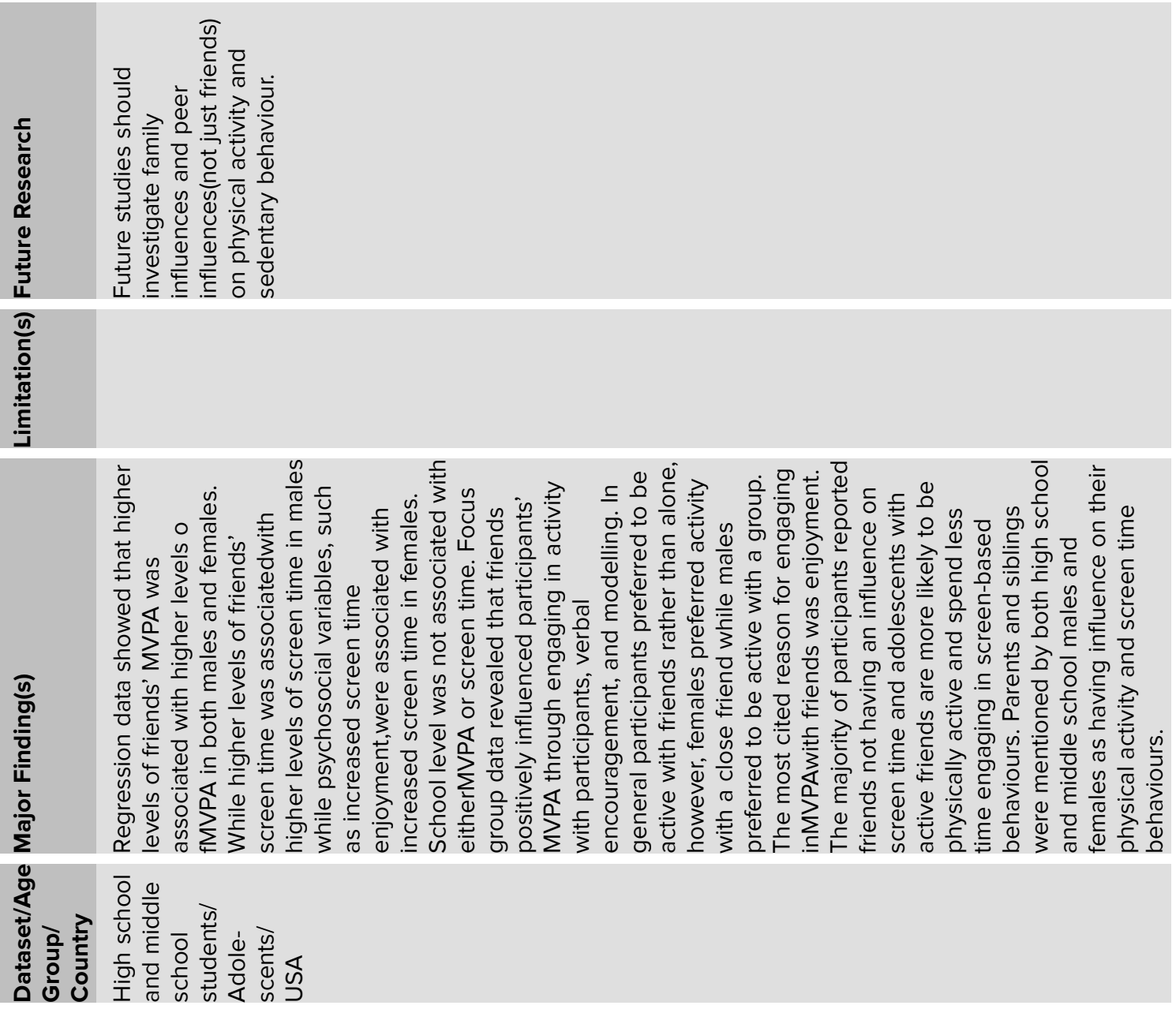

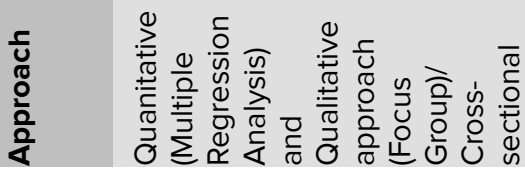
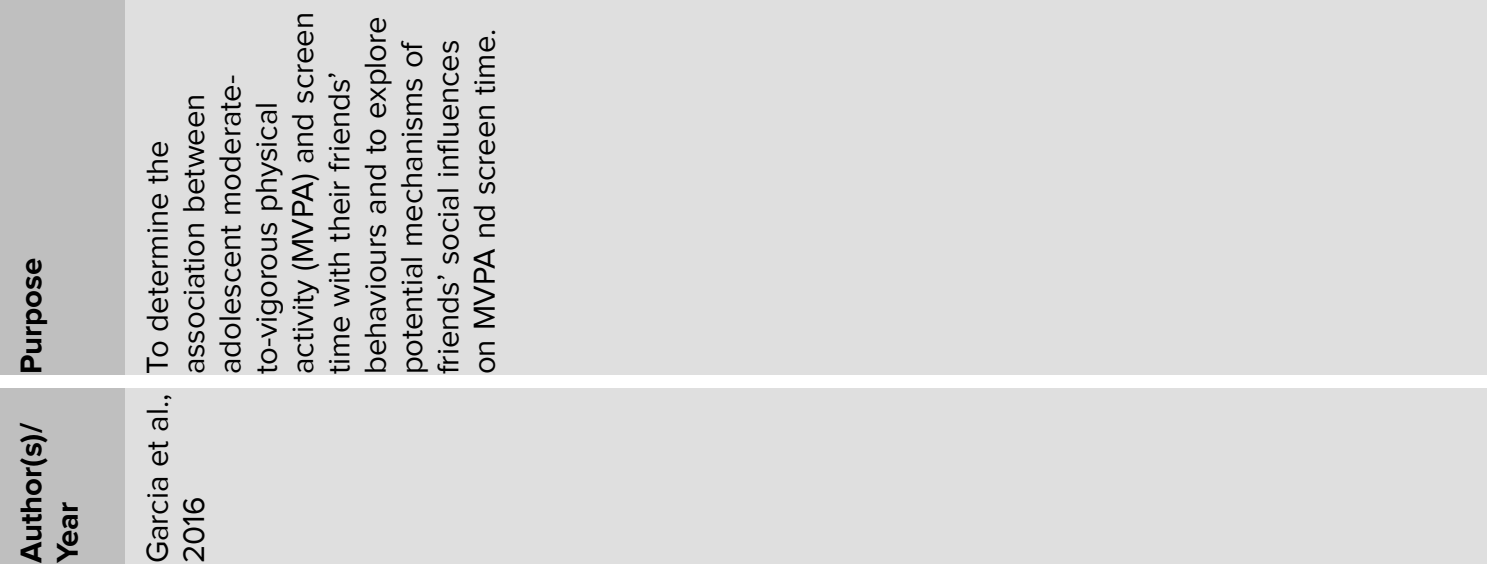

\begin{tabular}{|c|c|}
\hline 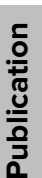 & 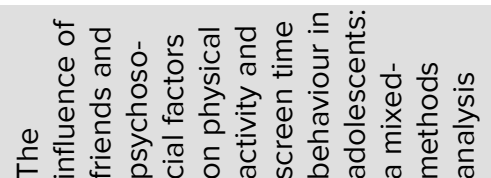 \\
\hline & N \\
\hline
\end{tabular}




\section{旁亳}

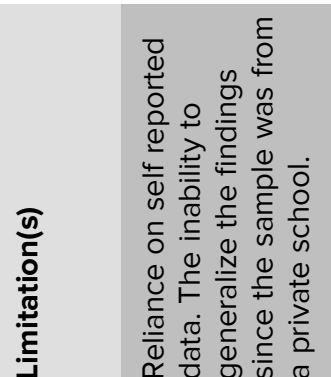

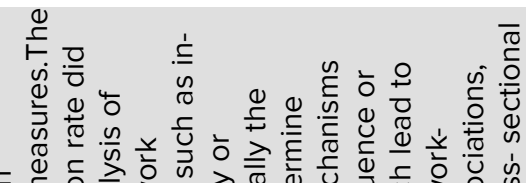

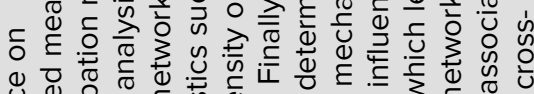

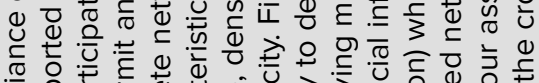

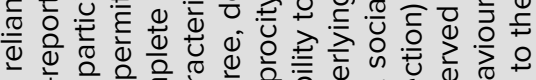

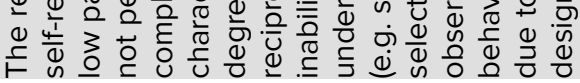
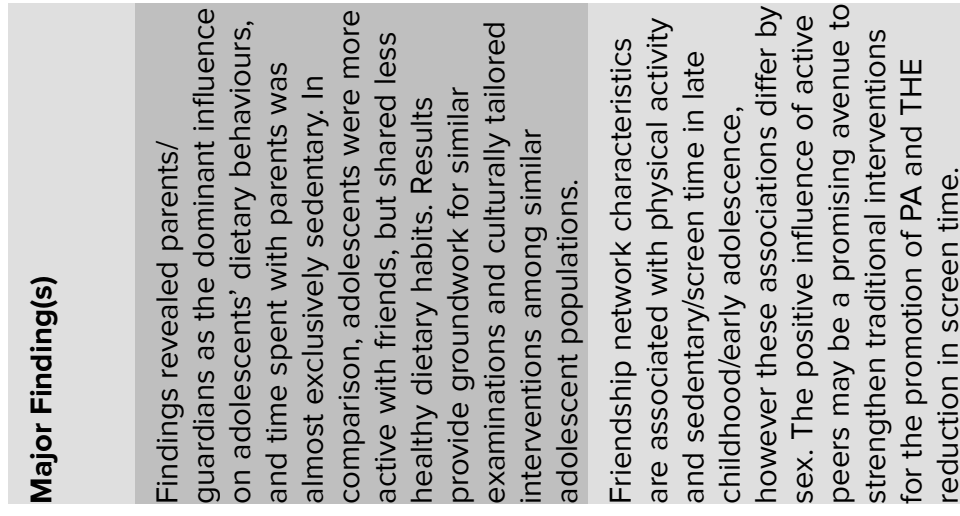

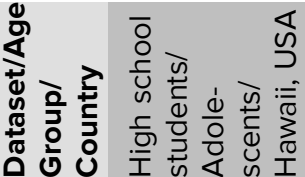

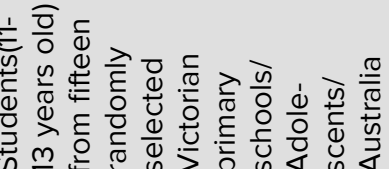
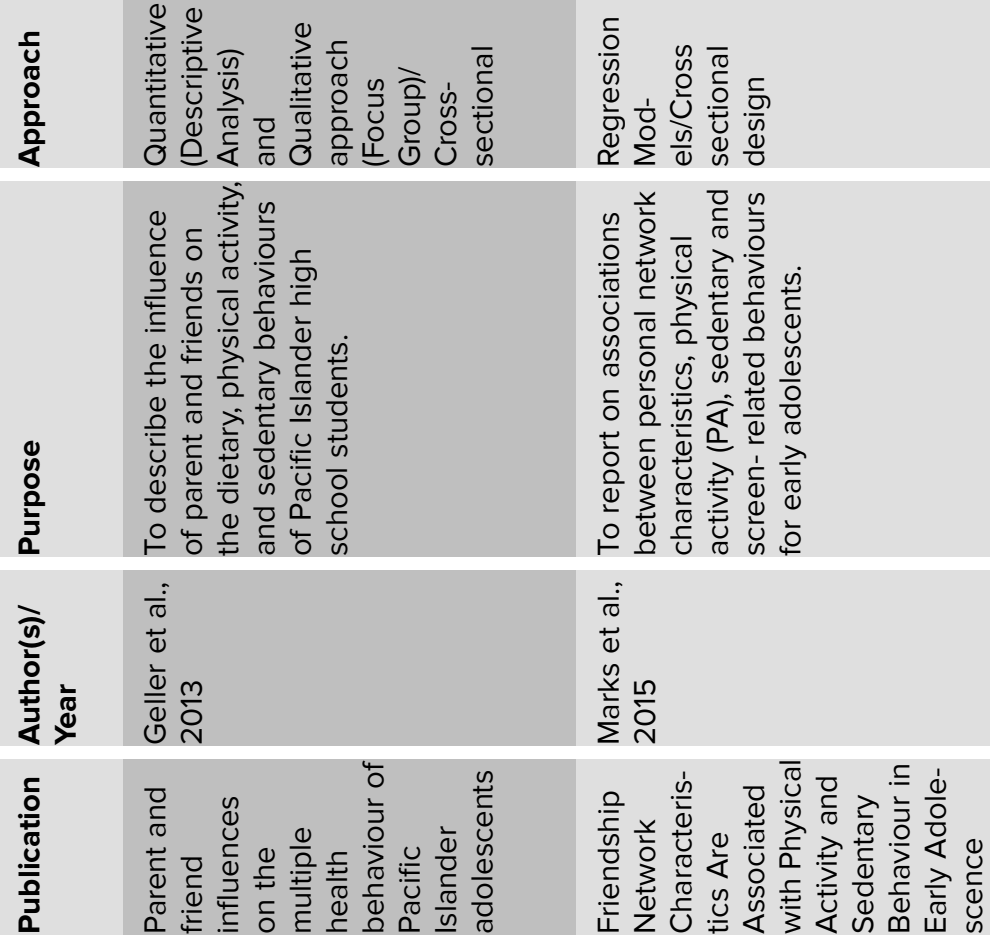

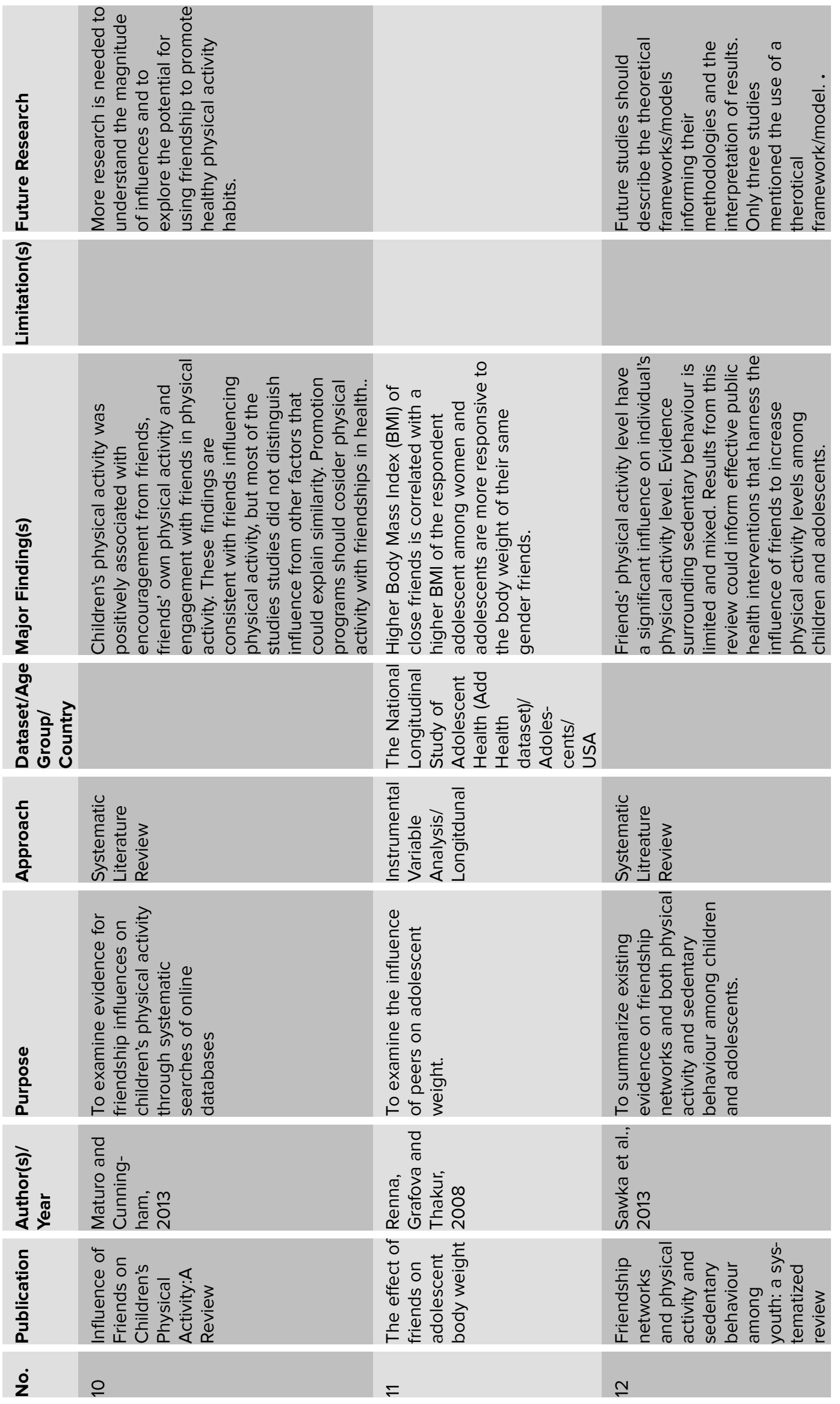

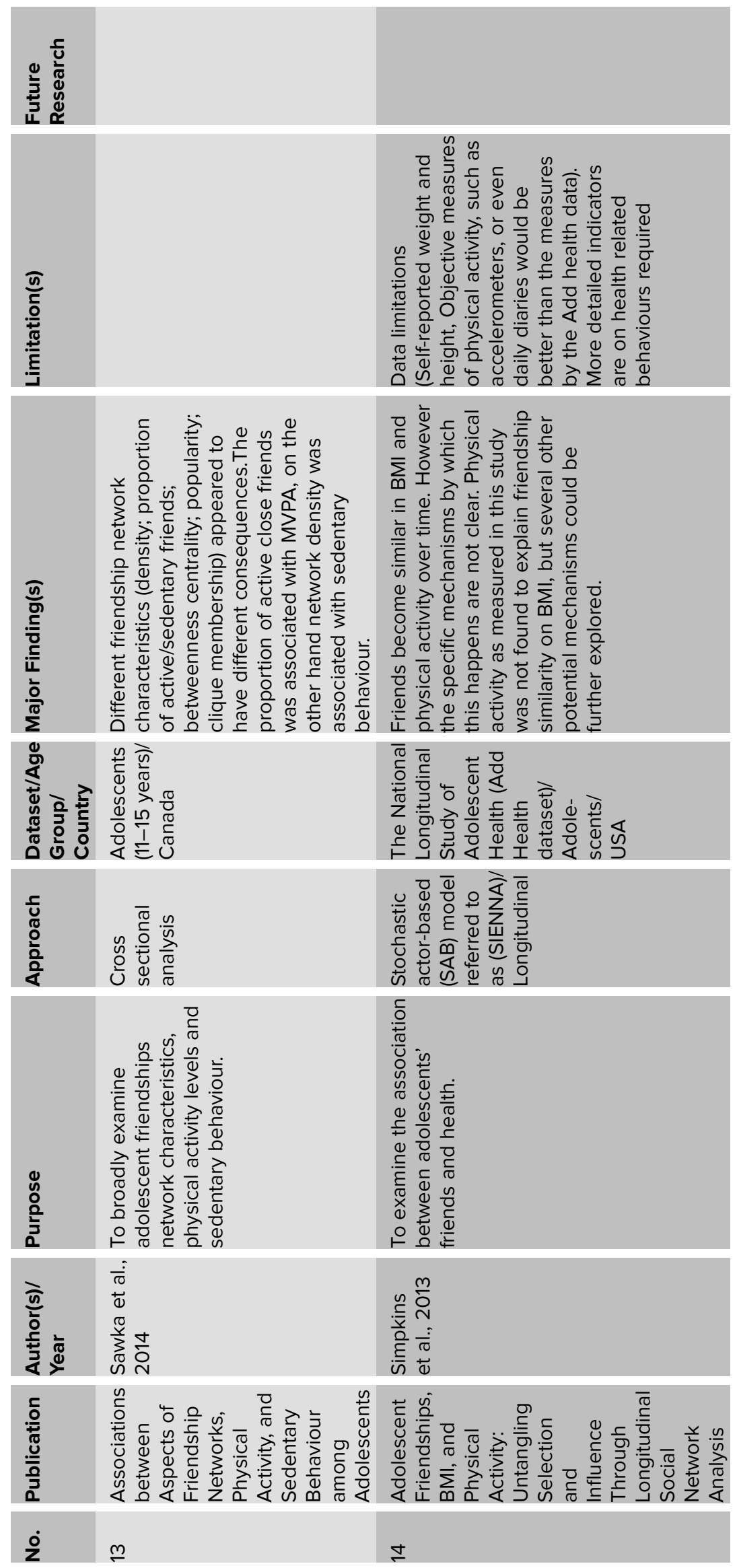
[3] Bahr, D., Browning, R., Wyatt, H. and Hill, J. (2009). Exploiting Social Networks to Mitigate the Obesity Epidemic. Obesity, 17(4), pp.723-728.

[4] Barclay, K., Edling, C. and Rydgren, J. (2013). Peer clustering of exercise and eating behaviours among young adults in Sweden: a cross-sectional study of egocentric network data. BMC Public Health, 13(1).

[5] Burke, M. \& F. Heiland. 2006. Social dynamics and obesity. Public Policy Discussion

[6] Papers: Federal Reserve Bank of Boston 2006; No. 06-5.

[7] Christakis, N. and Fowler, J. (2007). The Spread of Obesity in a Large Social Network over 32 Years. New England Journal of Medicine, 357(4), pp.370-379.

[8] Cohen-Cole, E. and Fletcher, J. (2008). Is obesity contagious? Social networks vs. environmental factors in the obesity epidemic. Journal of Health Economics, 27(5), pp.1382-1387.

[9] de la Haye, K., Robins, G., Mohr, P. and Wilson, C. (2010). Obesity-related behaviours in adolescent friendship networks. Social Networks, 32(3), pp.161-167.

[10] de la Haye, K., Robins, G., Mohr, P., \& Wilson, C. (2011). How physical activity shapes, and is shaped by, adolescent friendships. Social Science \& Medicine, 73(5), 719-728.

[11] de la Haye, K., Robins, G., Mohr, P. and Wilson, C. (2013). Adolescents' Intake of Junk Food: Processes and Mechanisms Driving Consumption Similarities Among Friends. Journal of Research on Adolescence, 23(3), pp.524-536.

[12] Finnerty, T., Reeves, S., Dabinett, J., Jeanes, Y. and Vögele, C. (2009). Effects of peer influence on dietary intake and physical activity in schoolchildren. Public Health Nutr., 13(03), p.376.

[13] Freeman LC. The Development of Social Network Analysis. Vancouver: Empirical Press; 2004.

[14] Garcia, J., Sirard, J., Deutsch, N. and Weltman, A. (2016). The influence of friends and psychosocial factors on physical activity and screen time behaviour in adolescents: a mixed- methods analysis. J Behav Med.

[15] Geller, K., Hendricks, T., Alvarez, A., Braceros, K. and Nigg, C. (2013). Parent and friend influences on the multiple health behaviour of Pacific Islander adolescents. Health, 05(11), pp.5-11.

[16] Grant, M. and Booth, A. (2009). A typology of reviews: an analysis of 14 review types and associated methodologies. Health Information \& Libraries Journal, 26(2), pp.91-108.

[17] Hammond, R. (2010). Social influence and obesity. Current Opinion in Endocrinology, Diabetes and Obesity, 17(5), pp.467-471. 
[18] Hernandez, L. and Blazer, D. (2006). Genes, behavior, and the social environment. Washington, DC: National Academies Press.

[19] Marks, J., de la Haye, K., Barnett, L. and Allender, S. (2015). Friendship Network Characteristics Are Associated with Physical Activity and Sedentary Behaviour in Early Adolescence. PLOS ONE, 10(12), p.e0145344.

[20] Maturo, C. and Cunningham, S. (2013). Influence of Friends on Children's Physical Activity: A Review. Am J Public Health, 103(7), pp.e23-e38.

[21] Maume, D. (2013). Social Ties and Adolescent Sleep Disruption. Journal of Health and Social Behaviour, 54(4), pp.498-515.

[22] Nam, S., Redeker, N. and Whittemore, R. (2015). Social networks and future direction for obesity research: A scoping review. Nursing Outlook, 63(3), pp.299-317.

[23] Pinheiro, F., Santos, M., Santos, F. and Pacheco, J. (2014). Origin of Peer Influence in Social Networks. Phys. Rev. Lett., 112(9).

[24] Powell, K., Wilcox, J., Clonan, A., Bissell, P., Preston, L., Peacock, M. and Holdsworth, M. (2015). The role of social networks in the development of overweight and obesity among adults: a scoping review. BMC Public Health, 15(1).

[25] Prinstein, M. J., \& Dodge, K. A. (2008). Understanding peer influence in children and adolescents. New York, NY: The Guilford Press.

[26] Renna, F., Grafova, I. and Thakur, N. (2008). The effect of friends on adolescent body weight. Economics \& Human Biology, 6(3), pp.377-387.

[27] Sawka, K., McCormack, G., Nettel-Aguirre, A., Hawe, P. and Doyle-Baker, P. (2013). Friendship networks and physical activity and sedentary behaviour among youth: a systematized review. Int J Behav Nutr Phys Act, 10(1), p.130.

[28] Sawka, K., McCormack, G., Nettel-Aguirre, A., Blackstaffe, A., Perry, R. and Hawe, P. (2014). Associations between Aspects of Friendship Networks, Physical Activity, and Sedentary Behaviour among Adolescents. Journal of Obesity, 2014, pp.1-12.

[29] Shoham, D., Tong, L., Lamberson, P., Auchincloss, A., Zhang, J., Dugas, L., Kaufman, J., Cooper, R. and Luke, A. (2012). An Actor-Based Model of Social Network Influence on Adolescent Body Size, Screen Time, and Playing Sports. PLOS ONE, 7(6), p.e39795.

[30] Shoham, D., Hammond, R., Rahmandad, H., Wang, Y. and Hovmand, P. (2015). Modeling Social Norms and Social Influence in Obesity. Current Epidemiology Reports, 2(1), pp.71-79.

[31] Simpkins, S., Schaefer, D., Price, C. and Vest, A. (2013). Adolescent Friendships, BMI, and Physical Activity: Untangling Selection and Influence Through Longitudinal Social Network Analysis. Journal of Research on Adolescence, 23(3), pp.537-549. 
[32] Tonetti, L., Fabbri, M., Martoni, M., Anderlucci, L., Filardi, M. and Natale, V. (2014). Relationship between sleep time preference of adolescents and their parents. Biological Rhythm Research, 45(6), pp.875-884.

[33] Valente, T. W. (2010). Social networks and health: Models, methods, and applications. Oxford; New York: Oxford University.

[34] Wadden, T., Brownell, K. and Foster, G. (2002). Obesity: Responding to the global epidemic. Journal of Consulting and Clinical Psychology, 70(3), pp.510-525.

[35] Wang, Y. and Lobstein, T. (2006). Worldwide trends in childhood overweight and obesity. International Journal of Pediatric Obesity, 1(1), pp.11-25.

[36] Wasserman, S. and Faust, K. (1994). Social network analysis. Cambridge: Cambridge University Press. 